\title{
Application of Block Chain Technology in the Financial Industry and Its Legal Norms
}

\author{
Xiaowei Zhou; Junnan Dong; Xinyin Zhang; Pei Zhang \\ Shaanxi Normal University International Business School \\ Xi'an, China \\ E-mail:461067351@qq.com
}

\begin{abstract}
Financial block chain technology is a frontier technology of financial science and technology, which plays an important role in the business processing and expansion of commercial banks under the background of Internet. This paper introduces the applications of block chain including the application of the three types of block chain, namely, digital currency block chain 1.0, intelligent contract block chain of 2.0, and block chain 3.0. In addition to the financial sector, the relationship between block chain and Internet finance is also expounded. Then, mainly through the case of bitcoin, the application of financial block chain has been or will be legislative and regulatory, which can lead to legal issues like lack of legislation, specific regulatory issues, privacy security issues, monopoly and technical problems. Finally, this paper analyzes the legal problems and puts forward some suggestions to relieve the legal problems caused by the application of financial block chain.
\end{abstract}

Keywords-Financial; Block chain technology; Legal; Application

\section{INTRODUCTION}

Financial institutions are generally applied based on the three characteristics of block chain technology. First, the weak centralization of block chain can simplify financial service and financial management process. Second, based on the untamable characteristics of the block chain, the account opening, registration, settlement and liquidation system can be built to digitize consumer assets, physical assets and virtual service assets. Third, based on the characteristics of open source of block chain technology, smart contracts can be constructed, such as certification, medical treatment, insurance, political voting, etc. Melanie Swan (2015) believes that the application of block chain technology can be divided into three stages: the first stage is mainly used in the monetary field, encrypted digital currency and digital payment system related to cash, etc. The second stage is mainly used in contract fields, such as stocks, bonds, credit, asset confirmation and smart contracts. The third stage is mainly applied to government, health, science, culture and art, and finally realizes weak centralization and social autonomy. At present, the application of block chain technology is mainly in the first and second stages.

Stage 1: block chain + digital currency
Block chain technology application in the field of currency and virtual currency is a delegate with COINS series, chain blocks in the application of the currency is through a ring by ring confirmation include transaction data blocks, to be irreversible, and the undisputed the purpose of the confirmation. This accounting model can meet the needs of the market by achieving a desire to connect dots. In this phase, in short, block chain technology is a kind of distributed technology of charge to an account, and the digital currency trading record on the chain be dispersed and saved, under the technology, data security and real-time has been effectively improved. Although their faces such as total price fluctuations, limited may cause deflation, energy waste, regulatory restrictions, and other problems, but it is still by far the most successful block chain technology application, and draw a picture of the ideal vision for people - the world's monetary unification, Hayek said nationalization of currency, the currency issue is no longer dependent on the central Banks.

The second stage: block chain + financial transactions, credit investigation

As an ownership registration and certification system, block chain is committed to realizing all market transactions and commercial credit behaviors. We can take a look at the more familiar areas of securities, futures, options and loans. In addition, some occasions that require credit investigation and smart contracts also have the use of block chain. For example, software such as itaifang is used to serve such occasions as rent and crowdfunding.

\section{ANALYSIS OF LEGAL PROBLEMS IN THE APPLICATION OF FINANCIAL BLOCK CHAIN}

In June of 2016, China's Internet banking association decided to set up block chain research group, by the bank of China, the former President Li lihui said coalesced, in-depth study block chain technology technical difficulties in the field of financial, business scenarios, risk management, industry standards, industry and regulatory issues. In the past, China's financial block chain focused on mining and hardware investment, and provided business and consultation with quotation and other information. There was a lack of in-depth research and a certain scale of application projects. Current industry began to appear to block chain diversified investment trends in the development of application and depth, but the small size and lack of large financial institutions, government 
support, Wan Xiang block chain laboratory is one of the few large institutions to support research and development projects, IDG and BEI investment of the more important block chain is domestic investment institutions. As the central bank pays more attention to the block chain and the technology spillover effect from developed countries becomes more and more obvious. China's relevant development will be accelerated.

In contrast to the accelerated development of financial block chain, China lags behind legislation, insufficient supervision and extensive operation of financial block chain technology represented by digital currency. Five ministries and commissions such as the people's bank of China in December 2013 issued the notice on preventing the risks of currency, prohibit financial institutions engaged in the business of digital currency such as COINS, but there is no risk conceit of individuals are prohibited to currency trading. In general, laws and regulations have not established a risk prevention and supervision system that can adapt to the characteristics of financial block chain. Under such circumstances, some financial block chains use to break the bottom line of financial regulation and regulation to conduct terrorist financing, network money laundering and network theft. Silk Road, an online market for illegal drugs, has been banned by law. The world's biggest currency exchange operator Mt. Bigger announced on February 28, 2014, 850000 COINS were stolen by trading platform, the company has to the Tokyo district court filed for bankruptcy protection; In June 2016 the etheric COINS to the center of the DAO (Decentralised Autonomous levels) project was attacked by hackers worth more than $\$ 50$ million in 3.5 million the etheric currency spill DAO wallet, etheric coin shrunk (ETH) market prices instantly, from the record high of $\$ 21.50$ to $\$ 15.28$, down more than 23\%; Bitcoin theft was first accepted in China in July 2016. Moreover, there has been rampant speculation and manipulation in the Bitcoin(BTC) and derivatives markets.

The brutal growth of digital money and the application of block chain finance has brought about increasingly prominent risk problems. Due to the integration of financial industry and Internet industry high risk attributes, block chain financial application by Internet diffusion speed faster, cross infection is more serious and harmful effects are more widely, risk supervision more difficult. Once the application risks of block chain finance occur, it is easy to cause serious losses and affect the security and stability of the financial system. Although the clarity, urgency and scale of the development of the block chain have not yet reached the need of comprehensive supervision of it, it is necessary to explore its principle, application and influence. Only by fully understanding the risks of the financial block chain can the regulatory authorities properly guard against and supervise the risks.

The general laws involved in block chain application are missing. The legal problems in the financial field involved in the block chain cannot be regulated and controlled by existing relevant regulations alone. The current application of laws and regulations involved financial block chain hierarchy complex, involve wide, have involved is the people's bank of China, the property law, the anti-money laundering law and the "regulations on the administration of the yuan" and so on, and just for digital currency. Other can involve specific laws and regulations "block chain + financial" only "electronic banking business management method", "the notice on preventing the risks of currency and on the guidance to promote the development of the Internet financial health, such as a few units, and basic it is released in the form of regulations or normative documents, there is less than the effect of prevention and control in advance, plus law inherent hysteresis, frequent use of the old" commercial bank law ", "securities law" and so on definition of the law, will make the application block chain caused by the problem is more serious, not only can make the legislation and regulators to suffer, It will also harm people's vital interests and discourage the enthusiasm and innovation of relevant participants in the block chain.

(1)In terms of the regulation of Internet finance in recent years, the problem of legal supervision in the application of block chain is really a state of "unreachable and unreachable". Similar to the lack of supervision of Internet finance, the supervision of block chain is even more impossible. To take a step back, "block chain + finance" is built on the basis of Internet finance, which is not firmly rooted. It is hard to expect the block chain to play its role under existing policies and structures.

(2)Block chain involving privacy security problems, if applied to block chain involved in the privacy of citizens in the financial sector, although decentralized public chain to ensure safety, but also will lose the department in charge of monitoring. Due to the public of all participating nodes in the chain of transaction data can be seen, the public will be able to track these deals, anyone can through the observation in the grid block chain drawing conclusions about STH, this legal privacy of individuals or institutions produce adverse effect; And if you use a centralized private chain, can guarantee that in the very great degree block chain control applied in the financial sector, with convenience in case of control node, however, the phenomenon of violations of the privacy security, it will be a pyrrhic victory. If it is not used properly in practice, the risk of "double-edged sword" of blockchain will be induced. Although the central bank released on December 27, 2016, the "measures for the implementation of financial consumer rights and interests protection of the people's bank of China, which for the protection of personal financial information has made the corresponding provisions, but blockchain is different from other Internet technology, is bound to the protection of financial information put forward higher requirements.

(3)Blockchain will also lead to the existence of monopoly problems. The block chain solution with workload proof faces $51 \%$ computational power attack problem. As the main body of the focused, will appear in objectively the actual master half computing power organization, if we do not try to regulate and control, monopoly situation easily happened, and this kind of monopoly, besides financial giants can cause by mastering high-end computing capacity of personal organization can also lead to. 


\section{POLICY SUGGESTIONS ON IMPROVING CHINA'S LEGAL SYSTEM OF AMOUNT BLOCK CHAIN}

Want to solve the problem of the application of the financial chain blocks, certainly will need government through legislation and regulation on the effective guidance, maintaining the order of financial markets, but cannot excessive regulation, which leads to its unable to play their own advantages. So in the process of regulating financial application block chain, should follow certain principles, to make the "block chain + financial" legal regulation to achieve the desired effect, promote the health of the financial innovation and economic benefit increase.

\section{A. Adhere to the legislative concept of innovation encouragement and appropriate standardization}

Whether it is the block chain technology itself or the integrated application of block chain + finance, all countries are at the exploratory stage and its technical rules are constantly being explored and changed. For these innovations, which are still in the early stage of development and are not fully mature in technology, legislators should adhere to the legislative concept of encouraging innovation and appropriate intervention. On the one hand, to delimit the technical innovation and the financial sector use legal bottom line, such as for technology developers must fulfill anti-money laundering obligations, formulates the reasonable risk management plan, perfecting the financial consumer protection measures, etc., to ensure not occur systemic financial risk, protect the consumers' rights and interests. For block chain, on the other hand, the application of the financial model, details technical regulations, standards, and some laws and regulations have not been clear fuzzy zone, as far as possible to be inclusive, can draw lessons from the financial behavior regulator (FCA) regulatory sandbox mode, by providing a smaller version of a true market, allowing companies to try modes of innovative products and services, and avoid the product defect and risk danger in time. On the basis of summarizing the experience unceasingly, further grasp the essence of innovation, assessment of risk, decisionmaking the future open area, and communicate with the industry, on the basis of a corresponding legal rules and regulatory arrangements.

\section{B. Respect the autonomy of the meaning and guide the self- discipline of the industry}

The participants' participation, collective autonomy is one of the important characteristics of block chain technology, whether chain blocks in constituting the technical regulations, alteration, maintenance, or special circumstances of emergency disposal, all participants need to form the broadest consensus. Legislators should fully respect the autonomy on one hand, allows the block chain participants maximum play to subjective initiative, block chain optimization technology norms, rules and autonomy and give participants recognized the legal status of habits or rules, encourage technology innovation. Legislators and regulators, on the other hand, also want to consciously guide block chain technology, all kinds of main body, form a self-discipline organization or industry alliance, at the legislative level industry self-discipline organization legal status and rights, to resolve the deadlock, common block chain community governance gradually explore block chain technology application in the field of financial and other technical standards, data specification, code of conduct. Such as, actively planning can meet the demand of China's financial market, commercial Banks and non-bank financial institutions are widely in SC/BC alliance, accelerate the formation of SC/BC standards in our country, at the same time actively strengthen the pilot application block chain, to ensure that our country gain proper position in the chain of blocks technical application.

\section{Conduct in-depth observation and research and adopt gradual legislative norms}

Regulation and legislation have always lagged behind technological innovation, and there is also a lack of mature institutional arrangements for blockchain financial regulation around the world. Block chain perfect financial legal system, therefore, need to lawmakers and regulators studying block chain technology and application mode, the operating principle of the financial sector parties to listen to opinions and Suggestions of industry institutions, and strengthen the international experience of absorption and comparison. We can learn from the concept of soft law governance. In the early stage of industrial development, more non-mandatory normative documents, such as guidelines and technical guidelines, will be issued, giving full play to the guiding role of industry self-discipline. Where legal conflicts are involved, a pilot program authorized by the National People's Congress may be used to give priority to some areas. During the trial period of the system, problems were tracked and observed, and regulatory arrangements were flexibly adjusted to give more space for the development of the industry. On the basis of summing up experience, and gradually to regulate block chain financial self-discipline rules and normative documents to rise to the regulations and administrative rules and regulations or laws, eventually form conforms to our country actual, fit block chain finance development characteristics, within the scope of the international advanced legal system.

\section{CONCLUSION}

The birth and application of block chain determines the height it can reach. It will not only become a new Internet revolution, but also lay a solid foundation for a paperless and intelligent society in the future. The rapid development of blockchain finance challenges the existing financial supervision and legal system. This paper introduces the current block chain financial model, the main application of combed the block chain financial development faces legal problems, and put forward the policy Suggestions of perfecting our country's block chain financial legal system. Prior regulation does not necessarily mean that it will be at the cost of restraining market vitality. Good technology and business innovation will inevitably require the state to propose more targeted regulations to achieve the regulatory purpose of economic law. We should not only take technical governance as a reference, but also attach equal importance to both technical governance and legal governance to better and faster 
keep pace with the financial block chain innovation under the current situation of globalization.

\section{REFERENCES}

[1] [Zhou Meili, Gu Chenjie,Li Min. Research on legal issues of block chain finance [J]. Financial review, 2017 (08):69-76.

[2] [Gao Yun. research on legal issues in the application of financial block chain in China [D]. Lanzhou University of finance and economics, 2017.

[3] Huang Rui. Regulatory research on financial block chain technology [J]. Academic BBS, 2016, 39(10):53-59.

[4] Gong Xiaolin, Yang Wang, Qu Shuangshi. Technical principles of block chain and its application in the financial field [J]. International finance, 2017(02):46-54.

[5] Yang Dong and Pan Zhao dong. Block chain brings financial and legal optimization [J]. China finance, 2016(08):25-26.

[6] Zhou Ruimin, Zhang Wenxiu. Risk and control analysis of financial technology innovation-research based on big data, artificial intelligence and block chain $[\mathrm{J}]$. China management informatization, 2017, 20(19):33-36.

[7] Chen Yixian. Research on the "impossible triangle" of block chain technology and problems needing attention [J]. Zhejiang finance, 2016(02):17-20+66.

[8] Lin Xiaoxuan. Application of block chain technology in financial industry [J]. China finance, 2016(08):17-18 